\title{
Maximizing Gain of Advancement Expanded Flaps by Both Vertical and Horizontal Back Cuts in Cases of Post Burn Deformities
}

\author{
NAHED SAMIR, M.D. and SHEREEN M. ABOUL FOTOUH, M.D. \\ The Department of Plastic and Reconstructive Surgery, Faculty of Medicine, Ain Shams University, Cairo, Egypt
}

\begin{abstract}
Background: Tissue expansion can be considered one of the fundamental steps in reconstruction ladder. It is a technique that can provide similar tissues to the defect without sacrificing other tissues. Tissue expansion offers lots of benefits, it provides tissue similar in texture and colour for coverage of defects especially post burn deformities. The high percent of complications and need of multiple stages has always been an obstacle to this technique. However in limited donor areas application of large expanders is very difficult and the gain of small expanders is limited with need of repeated sessions with its high complications and risks. In this study, we use rectangular expanded flaps which yields tissues more than other circular or crescent expanders and backcuts are added in order to increase both length and width of the flap.
\end{abstract}

Aim of Work: To study the value of both vertical and horizontal back-cuts added to expanded advancement flaps in reconstruction of post burn deformities in safe and effective way.

Patients and Methods:

- Twenty expanders were used for 16 patients as two expanders were applied in 4 cases. The expanders were implanted in the scalp $(n=10)$, neck $(n=3)$, chest and abdomen $(n=3)$ and shoulders $(n=4)$. Rectangular expanders were used in all cases. The capacity of the expanders employed varied from 250 to $750 \mathrm{ml}$.

- Cases were divided into two groups. In group A; we did two horizontal back cuts located at the base of expanded flap at the time of expander delivery while in group B; a third vertical backcut was added on the distal limb of the flap.

- The measurement of length of expanded flap is measured before doing any back cut and after the two horizontal backcuts in group A. It is also measured before and after all back cuts in group B.

- Results during 3 years period from 2015-2017, 16 cases were subjected to application of 20 rectangular expanders for reconstruction of post burn scarinng of different parts of the body, cases were divided into two groups complications included infection, port exposure, and superficial flap necrosis of the edges. In group A measurement of the length of expanded skin was done before and after horizontal back cuts for both vertical limbs AC, BD. In group B measurement was taken for the same limbs before and after all the 3 backcuts. The average increase in length in group; $\mathrm{A}=3.12 \pm$ $\mathrm{cm}$, while the average increase in group; $\mathrm{B}=4.35 \mathrm{~cm}$.
Conclusion: Using both vertical and horizontal back cuts added to both length and width of expanded flap gain, enabled us to remove more scarred tissue bilaterally. It also preserved normal tissues infront of the scarred tissue from being discarred.

Key Words: Expanded flaps - Back cuts - Post Burn deformities.

\section{INTRODUCTION}

The use of tissue expanders to obtain extraskin for repair of soft tissue defects and deformities was first introduced by Neumann, 1957 and followed by Radovan, 1982. On the same year, Austard and Rose 1982 introduced a self-inflating expander. Tissue expansion can give extra skin for reconstruction and reparative purposes of different parts of the body such as face, scalp, neck, trunk and extremities [1-3].

A lot of surgeons believe that the strongest indication for tissue expansion is the repair of scalp defects due to post burn alopecia, this is well understood as there are no other tissues that can simulate the scalp in its composition. Other conventional techniques such as rotational flaps, serial excision, free microvascular transfer and hair transplantation have many drawbacks. Complications such as flap necrosis, long operations, long hospital stay and excessive scarring are not uncommon $[4,5]$.

However, the technique of tissue expansion also have some disadvantages including two stage operation and also the expansion period which is difficult in some cases especially in children. There are several important steps such as; the choice of the expander location, size, shape and site of application of expander port for the success of this procedure. Also these steps are important for decreasing complications and getting best benefit of the expansion process $[\mathbf{5 , 6 ]}$. 
Julien 1987 stated that in selection of the proper size of implant the most serious problem is the discrepancy between shapes, sizes and volume of different kinds of tissue expanders. Some other authors prefer to use only rectangular expanders larger than the lesion size while others use different shapes of expanders [7,8]. Motamed et al., 2007 stated that the added tissue gain with rectangular expanders may increase the choices possibilities for flap design [9].

Several authors had used back cuts to maximize the gain of expanded tissues in different shapes of expanders. Radovan, 1983 started years ago with single back cut. The exact location of the back cut is widely variable. Some authors use back cut at the base of expanded flaps. Others use back cuts on the point of maximum projection of expanded flap as the expandes area proximal to this cut covers the donor area while distal to it covers the scarred tissue. Several designs had actually been advocated aiming to maximize benefit of tissue expansion and minimizing scars $[\mathbf{8 , 1 0 , 1 1 ]}$.

In this study we used rectangular expanders as we believe it gives more abundant tissue than any other rounded or crescent expanders. We planned to do advancement flaps and use both vertical and horizontal back-cuts to maximize the gain of this flap after expansion, without jeopardizing its blood supply.

\section{Aim of work:}

To study the value of both vertical and horizontal back-cuts added to expanded advancement flaps in reconstruction of post burn deformities in safe and effective way.

\section{PATIENTS AND METHODS}

The study was conducted on 16 patients complaining of post burn scarring underwent Surgical Reconstruction in the Burn Unit of Plastic Surgery Department of Ain Shams University, in the period from 2015-2017. The patients' ages varied from 12 to 30 years (mean, $21.1 \mathrm{yr} \pm 0.3$ ), 10 patients were females and 6 males, and 9 of them were children.

Twenty expanders were used for 16 patients as two expanders were applied in 4 cases. The expanders were implanted in the scalp $(n=10)$, neck $(n=3)$, chest and abdomen $(n=3)$ and shoulders $(n=$ 4). Rectangular expanders were used in all cases. The capacity of the expanders employed varied from 250 to $750 \mathrm{ml}$. Rectangular expanders are believed to have more expandability compared to crescent and round ones, also need less incision lines during their release and reconstruction, resulting in less scarring.
The patients are divided into two groups group A: In which the technique of delivery includes only two horizontal back cuts while in group B; a third vertical back cut is added. Each group 8 patients on which 10 expanders were used.

In the pre-operative visits, the dimensions of the scarred area were measured and the proposed donor site was evaluated carefully in order to estimate the size and dimensions of the needed expander and whether to apply one or two expanders. We chose the donor area as close as possible to the scarred tissue and in its longitudinal axis. The normal tissues infront and surrounding the scarred tissue are planned carefully in order to avoid discarding any tissues.

For pre-operative preparation, the patients took a shower with betadine shampoo and scrub the operation night. In cases of post burn alopecia the hair was examined and managed thoroughly to be free from lice. A prophylactic antibiotic was given to all the patients an hour before tissue expander insertion and removal procedures.

Planning of expander placement site: Tissue expander insertion operation was performed under general anesthesia. At first, the skin was prepped with betadine scrub and then painted with betadine paint.

Marking of the proposed expander pocket area which was designed to be $10-20 \%$ larger than the tissue expander base area was done. The incision line which is perpendicular to the donor site with $2 / 3$ of its length in scarred tissue was also marked. The incision line and the pocket area were infiltrated with 1/200000 adrenaline solution. After opening the incision line, the subcutaneous pocket (subgaleal pocket in donor area was dissected followed by fine hemostasis and washing of the pocket using normal saline. Before applying the tissue expander, it was washed with antibiotic solution $(500 \mathrm{ml}$ normal saline and $160 \mathrm{mg}$ gentamicin) and examined in terms of safety and leakage. Small suction drain was inserted first then the expander.

During the insertion procedure, complete unfolding of the prosthesis was assured. The injection port was placed under healthy skin in a location far from the pocket and the tissue expander. The location of the port must be under the subcutaneous tissue, accessible for the future injections and easily distinguishable, as over bone tuberosity if possible. Intra-operative inflation of $10 \%$ of the expander capacity was performed using normal saline after definitive closure of the incision. 
Post-operative inflation started 21 days after application, in twice weekly order, taking 2-3 months to approach $100-130 \%$ of the total expander capacity. The injection was done at the port site with the end point is either inflation of $10 \%$ of expander capacity or according to pain tolerance. This was assumed to cover more than double size of donor base dimension.

Operation of expander extrusion and advancement flap was done under general anesthesia. The surgical field was prepared. The expanded area was marked. Four limbs of the rectangle were marked AB is the base of the flap while both AC and $\mathrm{BD}$ are the two parallel vertical limbs while DC is the distal limb.

Three borders out of the four of the expanded rectangular tissue were cut first is (CD) the distal limb then the two vertical limbs down to the base of the flap. Delivery of the expander and its port was done. Minimal scorring was done. The thickened constricting band of the capsule at the distal tip of the expanded flap stripped to unfold the boxy tissue.

Using skin hooks the expanded flap was advanced to cover the scarred area. The first horizontal back cut was done from outward to inward incison down snip by snip with checking of flap edge vascularity the flap will advance gradually, this is followed by the opposite horizontal backcut which actually equalize the side rotation of the extremity of flap. This step is done in both groups.

Two triangles will be created by normal tissue at the base of the flap, these triangular tissues are actually excess tissue that will form dog ears especially in the scalp. These tissues are never touched and banked as tissue reservoir.

All the back cuts were full thickness resulting in flattening of the flap converting it into a sheet rather than a constricted box. By these back cuts we can maximize the benefit of the expanded flap in longitudinal direction.

The expanded flap is sutured over the scarred tissue to be excised marking of the determined area to be carried on. The excision area was infiltrated with 1/200000 adrenaline solution. Excision and meticulous hemostasis was followed by insetting of the expanded, advanced flap. Final closure is done. In cases required two expanders, the same technique was repeated.

In cases of group B an additional vertical backcut is done on the the distal limb of the box (CD).
The site of back cut is planned more close to the middle of the limb and guided by normal tissues in front of the recepient site. This vertical backcut is also done snip by snip and add bilateral extra tissue that enable us to remove more scarred tissue from the recipient area. This back cut also helps to unfold the distal limb of the expanded flap to turn the flat sheet into a sheet of tissue with two wings longer without impairing its blood supply. The two wings will cover both infront and bilateral direction of the recipient area.

The measurement of length of expanded flap is measured before doing any back cut and after the two horizontal backcuts in group A. It is also measured before and after all back cuts in group $\mathrm{B}$ in order to estimate the added gain of the vertical back cut.

\section{RESULTS}

During 3 years period from 2015-2017, 16 cases were subjected to application of 20 rectangular expanders for reconstruction of post burn scaring of different parts of the body, cases were divided into two groups complications included infection followed expander application which responded to treatment by antibiotic in 3 cases. Portal exposure occurred in 3 expanders and in these cases we had to continue inflation through the port as external port. Slight superficial necrosis of the edges occured in 1 case in Group B, which didn't need surgical intervention (Table 1).

In group A measurement of the length of expanded skin was done before and after horizontal back cuts for both vertical limbs AC, BD. In group $\mathrm{B}$ measurement was taken for the same limbs before and after all the 3 backcuts. The average increase in length in group; $A=3.12 \pm \mathrm{cm}$, while the average increase in group; $\mathrm{B}=4.35 \mathrm{~cm}$ (Table 2).

Table (1): Complications in both groups.

\begin{tabular}{llc}
\hline & Group A & Group B \\
\hline Port exposure & 2 expanders & 1 \\
Thinning of expanded flap & 0 & 0 \\
Infection & 1 & 2 \\
Necrosis of edges & 0 & 1 \\
Hematoma after expander delivery & 0 & 0 \\
\hline
\end{tabular}

Table (2): Measurement of expanded flap length increase before and after backcuts in each group in cms.

\begin{tabular}{lcccccccccc}
\hline $\begin{array}{l}\text { No of } \\
\text { expander }\end{array}$ & 1 & 2 & 3 & 4 & 5 & 6 & 7 & 8 & 9 & 10 \\
\hline Group A & 3.5 & 2.5 & 3.3 & 3.1 & 2.9 & 3 & 2.8 & 3.4 & 3.2 & 3 \\
Group B & 4 & 4.1 & 5 & 4.5 & 3.5 & 4.2 & 4.7 & 4.4 & 4.6 & 4.5 \\
\hline
\end{tabular}



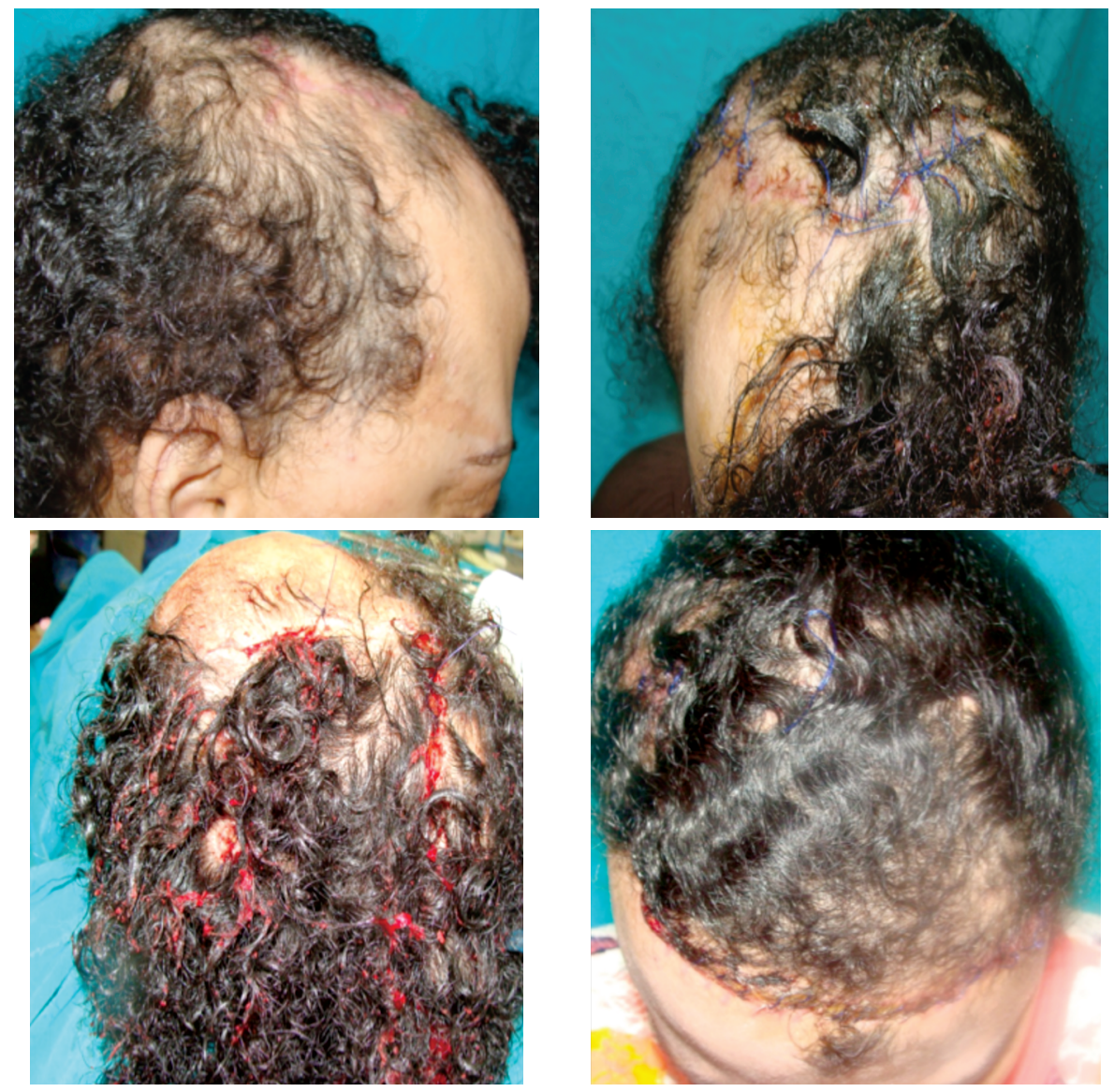

Fig. (1): Group A with double back cut at the base of the expanded flap.
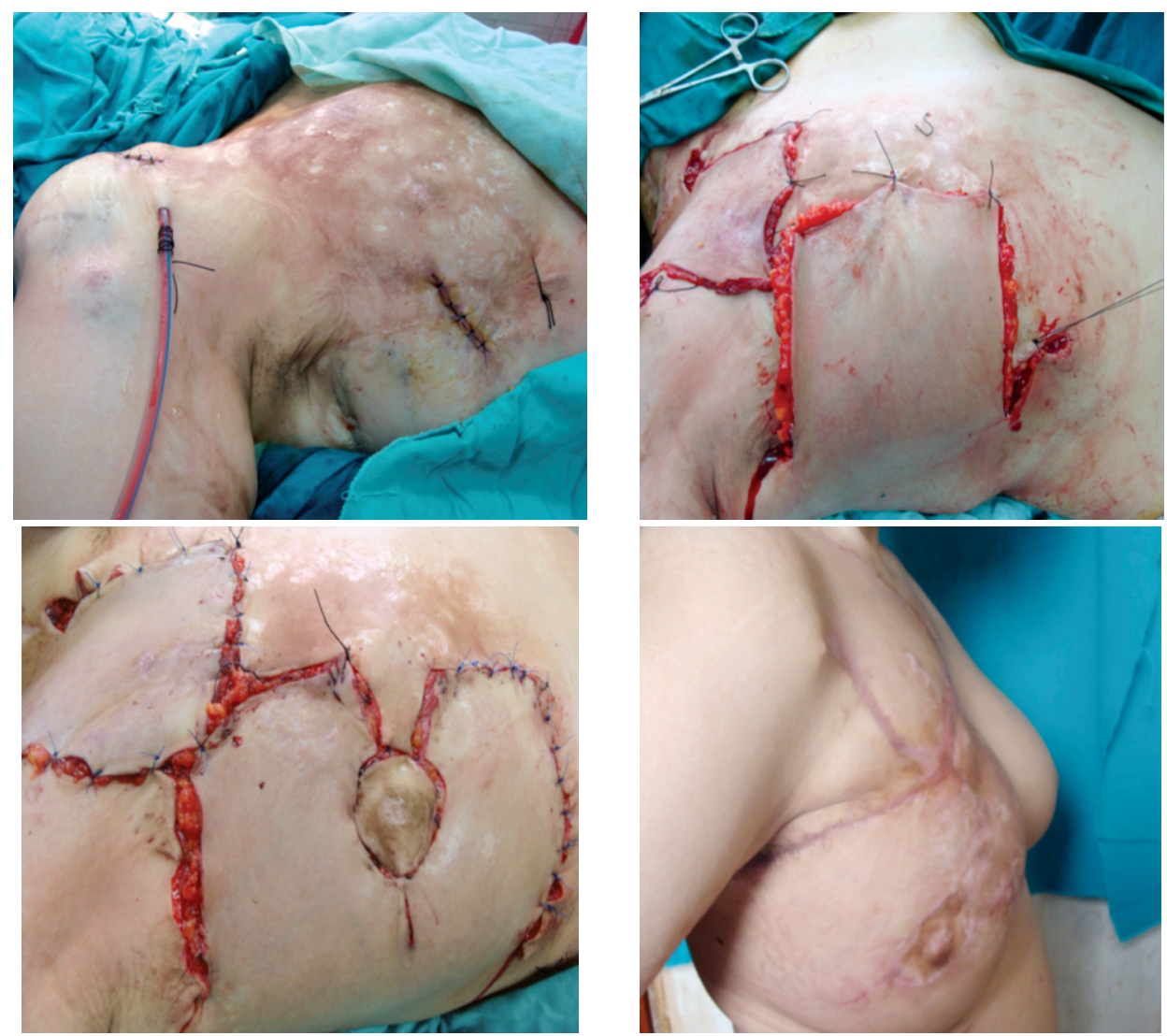

Fig. (2): Case of group B. 


\section{DISCUSSION}

Burns is one of the devastating condition in emergency medicine due to its physical and psychological scars, contactures and chronic disabilities. Tissue expansion has been described as an effective maneuver for reconstruction after trauma, burns and management of other lesions as giant hairy moles, except for unplanned major complications the only long term sequel is just incisional scar $[\mathbf{9 , 1 1}]$.

Choosing the appropriate size of expander has several mathematical calculations. Radovan 1983, Morgan and Edegerton 1985 used expander base same size as the defect to be reconstructed, Gibney 1984 recommended it to be 2.5-3 times the size of the defect while Manders et al., 1984 advised using size of expander as large as possible. Some authors uses expander size as small as $250-500 \mathrm{ml}$ while. Other studies used expanders reaching up to $95-3000 \mathrm{ml}$. There is wide range of variation regardind the appropriate shape of expanders and location of injection port according to different cases [10-17].

In our study we used expander base same size as the defect. Expander size ranged from 250$750 \mathrm{ml}$. In 4 cases we had to use two expanders instead of using one large expander as in post burn alopecia in children. The use of two expanders average size is much safer than big expanders which can lead to a lot of complications.

Several studies recorded wide range of complication rates following tissue expansion this range from $1.22 \%$ to $30 \%$ in other studies. The most common recorded complications included infection, exposure of tissue expander or injection port malposition, flap necrosis and shrinkage of tissue expander. Others as hematoma,seroma or failure of inflation. Some authors as kawashima recorded complication rate as high as $34.8 \%$ with ratio of prosthesis exposure $13 \%$ while other as Motamed et al., 2009 recorded only 2 cases of flap edges epidermolysis responeded to medical treatment [18-21].

Although in our study the complication rate in both groups together reached $35 \%$, but most of the complication didn't terminate the process of expansion. Three cases showed infection which responded to treatment by antibiotics. Partial and total port exposure occurred in three cases on which we continued the process of inflation as external port. One case showed superficial necrosis of flap edges in group B which was treated locally by wet ointments with no need for further excision.
Tissue expansion creates a three dimensional structure of the rectangular box (advanced rectangular expanders). Several steps has been used by different authors to get the maximum tissue of this three dimenstion rectangle. These steps include back cuts, capsulectomy or capsulotomy, also using different shapes of expanders. Zide and karp used double back cuts in the midlle of the side walls of the rectangle and continued up to the height the cuts were in front of each other,also used different shapes of expanders without mensioning the accurate or safe length of back cut. Hudson et al., 2003 did not do capsulectomy at all and did several horizontal back cuts 1-2 per side at the sites of surrounded normal tissue exist in addition to single back cut at the base of the flap [8-11].

In our study we avoided capsulectomy at all, we only removed strip at the distal edge of the flap (DC) in ordr to unfold the rotated edge which we believe to be safe also very minimal scoring of the capsule. We did two horizontal back cuts done snip by snip with testing blood supply of the flap edge before each snip. The length of horizontal back cuts not necessary to be symmetrical as we believe that the second back cut allows only rotation of the flap to neutralize rotation done by first cut. In group B we applied an additional single vertical back cut on (DC) line close as possible to the middle and if opposed by normal tissue this enable us to preserve the normal tissue from being discareded. This back cut didn't affect the vascularity of the flap and was completely safe. It increased the length of the flap between $1-1.5 \mathrm{~cm}$ also bilateral rotation of the distal end of the expanded flap allowed us to remove more scarred tissue laterally.

Back cuts are considered the horse player in this study which required very careful planning before chosing the right position of the expanders. The position of healthy tissues opposite the scarred tissue as the frontal hairline in cases of post burn alopecia helped in planning for the vertical back cut which added extra length to the flap and on the same time we didn't sacrifice normal tissue. Also in other cases of post burn scrring around the nipple in breast reconstruction, the vertical back cut allowed us to remove scarred tissue bilateral to nipple areola comlex without sacrificing this precious area. In group A we measured the length of expanded flap before and after the horizontal back cuts and the average increase in length was $3.12 \mathrm{cms}$. The site of the back cut at the base of the flap in crucial to turn the box shaped flap into a flat sheet. In group B the measurement before and after all back cuts was average $4.35 \mathrm{~cm}$. It was not only safe but also added extra precious length from 
single one operation with no need for repititon of expansion process.

\section{Conclusion:}

Using both vertical and horizontal back cuts added to both length and bilateral width of expanded flap gain. It also preserved normal tissues infront of the scarred tissue from being discarred. Single stage with one or two expanders according to size of scarred tissue was enough. The use of small expanders with maximizing the gain by back cuts is much more safe than using large expanders with risk of exposure or extrusion.

\section{REFERENCES}

1- Neumann C.: The expansion of an area of skin by progressive distension of subcutaneous balloon. J. Plast. Surg., 19 (2): 124-30, 1957.

2- Radovan C.: Breast augmentation after mastectomy using the temporal expander. Plast and reconstructive surgery, 69: 195, 1982.

3- Austard E.D. and Rose L.: A Self inflating tissue expander. Plast. Reconstr. Surg., 70: 588, 1982.

4- Chang T.S. and Jin: Application of tissue expansion in treatment of post-burn skin contractures and alopecia Eur. J. Plast. Surg., 9: 7-12, 1986.

5- Argenta L.C.: Controlled tissue expansion in reconstructive surgery. Brit. J. Plast. Surg., 37: 520, 1984.

6- Buhrer D.P., Huang T.T., Ye H.W. and Blackwell S.J.: Treatment of burn alopecia with tissue expanders in children. Plast. Reconstr. Surg., 81: 512, 1988.

7- Julien H.A. Van Rappard, M.D., J. Molenaar, Dr.Sc., K. Van Doorn, Med. Cand., G.J. Sonneveld and J.M.H.M. Borgohouts, M.D.: Surface area increase in tissue expansion plast and reconstructive, 1987.

8- Barry M. Zide D.M.D., M.D. and Karp N.S., M.D.: Maximizing gain from rectangular tissue expanders Vol.90,3, 1991.

9- S. Motamed*, F. Niazi, S. Atarian and A. Motamed: Postburn head and neck reconstruction using tissue expanders. Burns, 878-884, 2008.
10- Radovan: Tissue expansion in soft tissue reconstruction. Plast. Reconstr. Surg., 74: 59, 1983.

11- Hudson D.A.: Maximizing the use of tissue expanded flaps. The british association of Plastic Surgeons, 56: 784-790, 2003.

12- Morgan R.F. and Edergerton M.T.: Tissue expansion in reconstruction hand surgery: Case report J. Hand Surg., 10A: 754, 1985.

13- Gibney J.: Tissue expansion in reconstructive Surgery. Presented at the annual scientific meeting of the American society of plastic and reconstructive surgery, in las vegas, Nevada in October, 1984.

14- Manders E.K., Schenden M.J., Furrey J.A. and Hetzler P.T.: Soft tissue expansion: Concept and complications. Plast. Reconstructive Surg., 74: 493, 1984.

15- Motamed S. and Attarian Sh.: Cervicofacial angle reconstruction while insetting flaps to treat chronic burns. Pejouhandeh Shahid Beheshti Univ. Med. Sci., 14: 1, 2009.

16- Gao J.H., Ogawa R., Hyakusoku H., Lu F., Hu Z.Q., Jiang P., Yang L. and Feng C.: Reconstruction of the face and neck scar contractures using staged transfer of expanded "Super-thin flaps". Burns, 33: 760-3, 2007.

17- Mohammad Reza Ashab Yamin, Naser Mozafari, Mohadase Mozafari and Zahra Razi: Reconstructive Surgery of Extensive Face and Neck Burn Scars Using Tissue Expanders www.wjps.ir/Vol. 4/No. 1/January 2015.

18- Bozkurt A., Groger A., O'Dey D., Vogeler F., Piatkowski A., Fuchs P. and Pallua N.: Retrospective analysis of tissue expansion in reconstructive burn surgery: Evaluation of complication rates. Burns, 34: 1113-8, 2008.

19- Spence R.J.: An algorithm for total and subtotalfacial reconstruction using an expanded transposition flap: A 20-year experience. Plast. Reconstr. Surg., 121: 795-805, 2008.

20- Kawashima T., Yamada A., Ueda K., Asato H. and Harii K.: Tissue expansion in facial reconstruction. Plast. Reconstr. Surg., 94: 944-50, 1994.

21- Chun J.T. and Rohrich R.J.: Versatility of tissue expansion in head and neck burn reconstruction. Ann. Plast. Surg., 41: 11-6, 1998. 